\title{
Intravenous to oral stepdown implementation at the Calgary General Hospital, Calgary, Alberta
}

\author{
L HEULE BSCPharm, DW MEGRAN MD FRCPC, RR READ MD FRCPC, TJ LOUIE MD FRCPC
}

$I^{*}$ N THE PAST FIVE YEARS, HOSPITALS HAVE INITIATED A VARIETY of programs to facilitate the transition from intravenous to oral antimicrobial therapy. At the Calgary General Hospital, our belief is that the most cost-effective approach should be through a well-educated medical staff. This is because the primary individuals required to make the decision to stepdown therapy are the physician and the patient, minimizing the use of other institutional personnel in the process. However, it is not certain whether this is the most cost-beneficial approach. For the past five years, there has been no specific stepdown program, ie, use of innovative, easilynoticed chart reminders or clinical pharmacist intervention. Instead, a combination of quarterly antimicrobial newsletters, a four-day automatic stop order, annual antimicrobial cost/organism susceptibility cards and a strong infectious disease service promoting open dialogue with the medical staff have remained the cornerstones of a low-budget, nonlabour intensive, relatively nonintrusive program promoting rational antibiotic use.

A one-day point prevalence survey (November 1994) of all therapeutic (not prophylactic) antimicrobial use showed that 23\% of hospital inpatients (115 of 500) were receiving systemic antimicrobial therapy. Treatment modes included intravenous therapy (46\%), combined intravenous and oral therapy (12\%) and oral therapy alone (42\%). A two-week survey (December 1994) of therapeutic antimicrobial use showed that

Department of Pharmacy, and Division of Infectious Diseases, Departments of Medicine and MicrobiologyInfectious Diseases, The Calgary General Hospital, and the University of Calgary, Calgary, Alberta

Correspondence: Dr TJ Louie, Division of Infectious Diseases, Departments of Medicine and MicrobiologyInfectious Diseases, The Calgary General Hospital, Calgary. Alberta T2E OA1, telephone 403-268-9111, Fax 403-268-9222
$23 \%$ of patients were stepped-down from intravenous to oral therapy after a mean of five days' intravenous therapy. It is concluded that a 'passive' system is moderately successful in promoting stepdown therapy. The cost-benefits of a more proactive program, ie, special chart stickers/reminders, regular review by a drug utilization review pharmacist, or computerized application of clinical and/or laboratory guidelines using a hospital information system, are still to be determined.

Over the past four years, antimicrobial costs have been reduced $28 \%$ using a moderately restricted formulary (imipenem, ceftazidime, ceftriaxone), promotion of cost-effective choices and dosages (eg, cefazolin/ metronidazole, intravenous/oral to replace both clindamycin or cefoxitin where feasible), and informal encouragement of stepdown therapy. The utilization survey showed that it may be possible to shorten further the duration of intravenous therapy, eg, from five days to two to three days, and perhaps to increase the proportion of patients converted to oral therapy.

Although stepdown conversion is easiest going from agent to agent, ie, intravenous ciprofloxacin to oral ciprofloxacin, in clinical practice a spectrum-to-spectrum approach allows maximal flexibility accounting for cost, ease of use, and adverse drug reaction risks.

It is proposed to conduct a three month audit of all courses of therapeutic antimicrobial use without intervention (control period), following which the cost-benefits of active intervention using a drug utilization review pharmacist to promote stepdown therapy guidelines will be evaluated. This would be supplemental to the current broad-based educational/infectious diseases service approach. Determining the relative contributions of components of a rational antimicrobial use program will be important in a health care system that is balancing resource utilization and outcomes. 


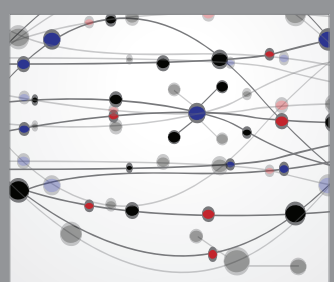

The Scientific World Journal
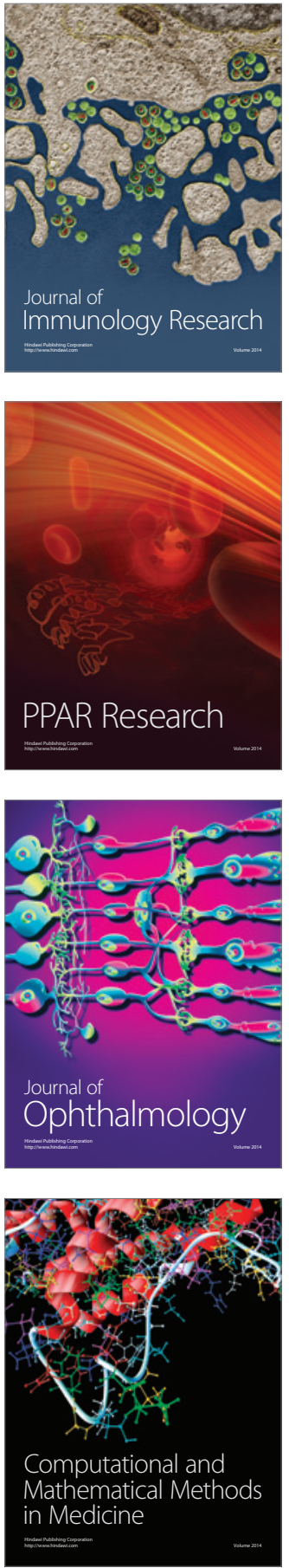

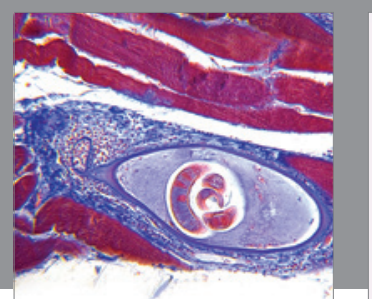

Gastroenterology Research and Practice

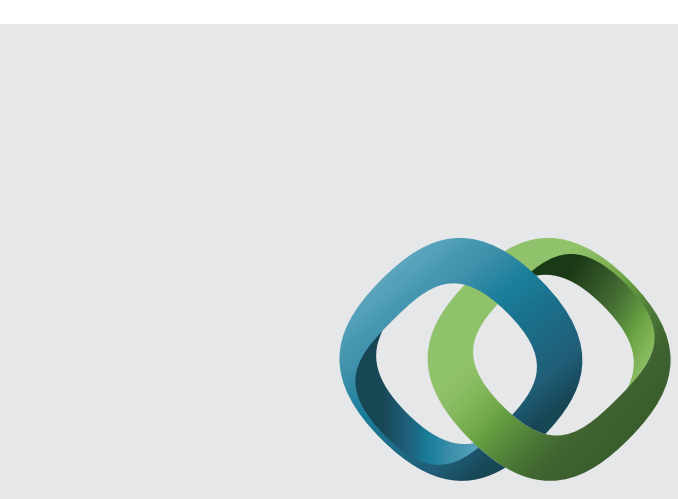

\section{Hindawi}

Submit your manuscripts at

http://www.hindawi.com
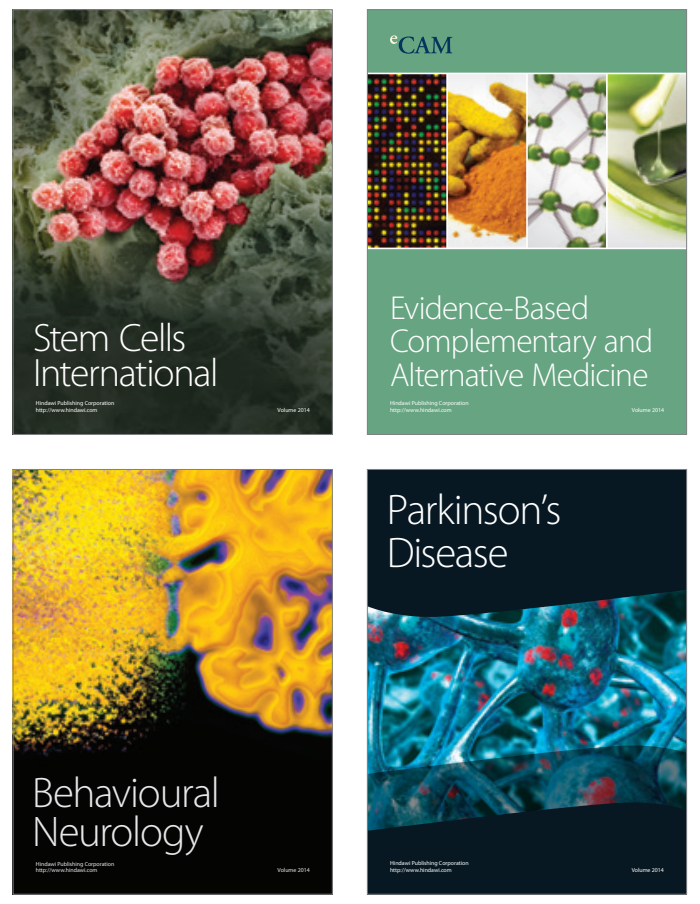
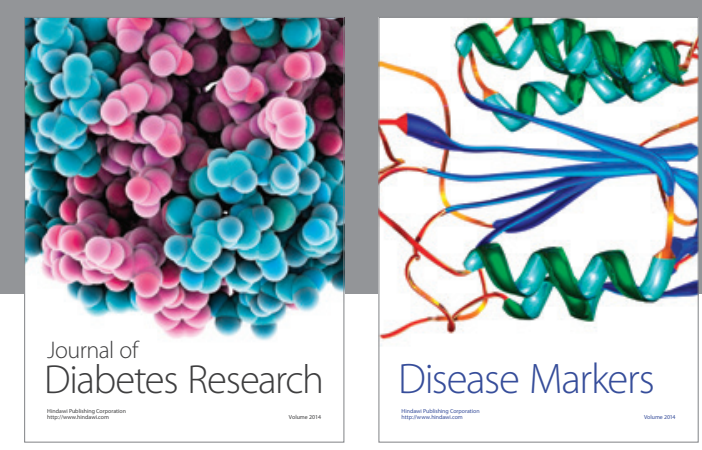

Disease Markers
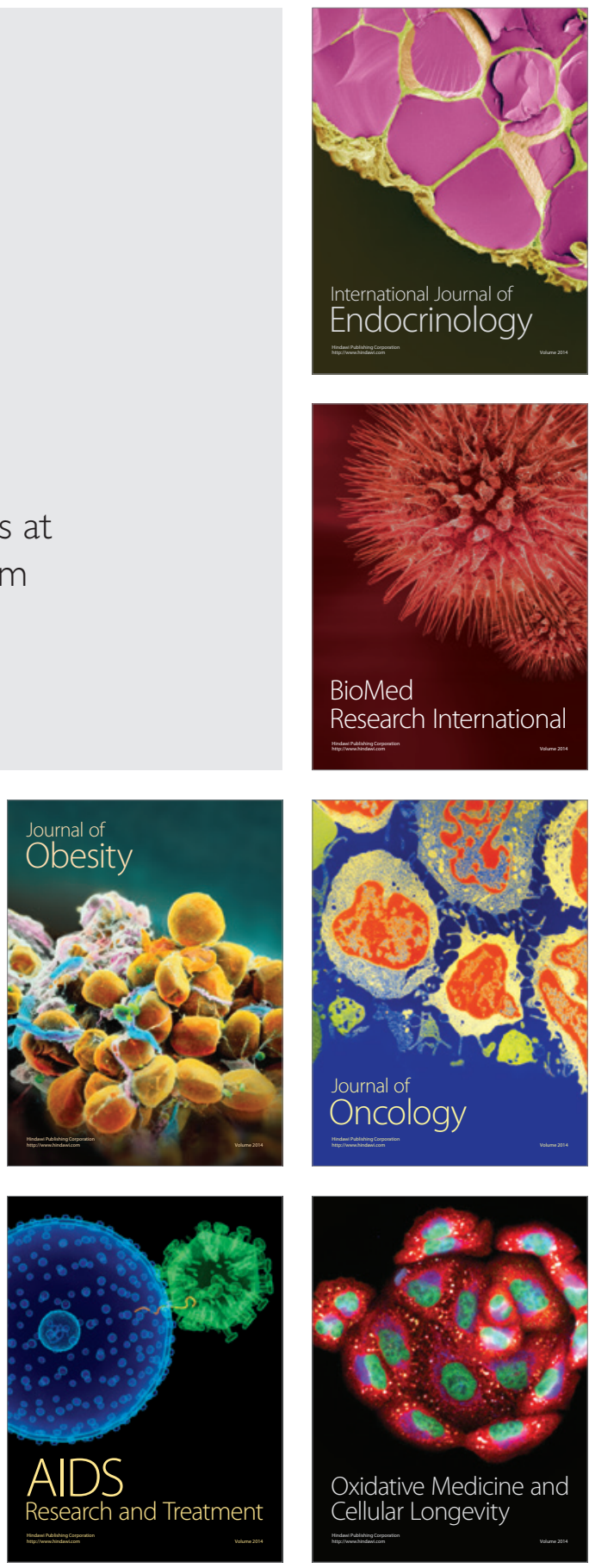